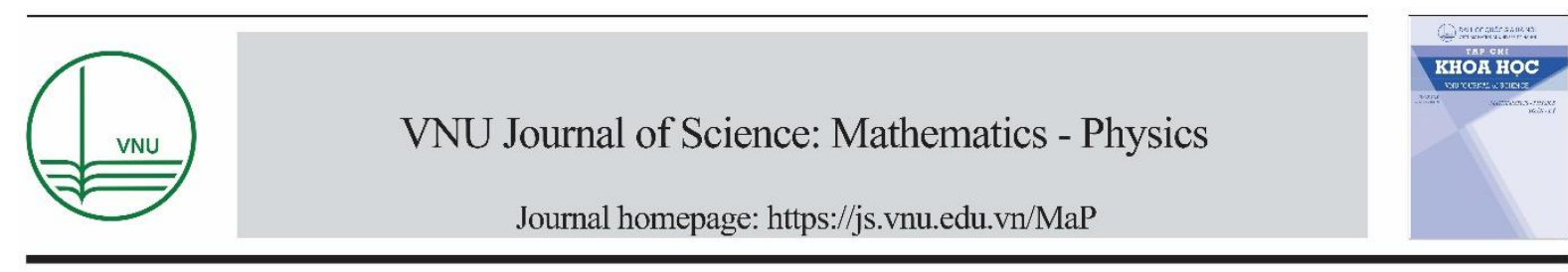

\title{
Original Article \\ Energy Level Locations of Lanthanide Ions in Strontium-Aluminosilicate Phosphors
}

\author{
Ho Van Tuyen*, Nguyen Ha Vi \\ Duy Tan University, 3 Quang Trung, Hai Chau, Da Nang, Vietnam
}

Received 05 August 2020

Revised 29 August 2020; Accepted 15 September 2020

\begin{abstract}
This paper determines the position of energy levels of lanthanide ions in $\mathrm{Sr}_{2} \mathrm{Al}_{2} \mathrm{SiO}_{7}$ (SAS) phosphor by a combining analysis of the lowest $4 \mathrm{f}-5 \mathrm{~d}$ transition of $\mathrm{Ce}^{3+}$ ions and the charge transfer of $\mathrm{Eu}^{3+}$ ions-doped SAS phosphor. The SAS samples were successfully synthesized via solid state reaction, and their structure phase was further confirmed by X-ray diffraction. In the case of $\mathrm{Eu}^{3+}$-doped SAS phosphors, the energy of the charge transfer (CT) transition of the $\mathrm{Eu}^{3+}$ is about $4.70 \mathrm{eV}(264 \mathrm{~nm})$ and this energy is applied to determine the position $4 \mathrm{f}$ level of all divalent lanthanides relating to the top of the valence band in the SAS host lattice. For $\mathrm{Ce}^{3+}$ activated SAS samples, the lowest $4 \mathrm{f}^{1} \rightarrow 4 \mathrm{f}^{0} 5 \mathrm{~d}^{1}$ excitation energy is determined around $3.71 \mathrm{eV}(334 \mathrm{~nm})$ and it is used to estimate the lowest $4 \mathrm{f}-5 \mathrm{~d}$ transitions for all lanthanide $(\mathrm{Ln})$ ions in host lattice. A broad band emission of the $5 \mathrm{~d} \rightarrow 4 \mathrm{f}$ transition of $\mathrm{Ce}^{3+}$ ions includes two peaks emission with different energy about $1997 \mathrm{~cm}^{-1}$ that coincides with the theoretical value of $2000 \mathrm{~cm}^{-1}$. The host referred binding energy (HRBE) diagram of all $\mathrm{Ln}^{2+}$ and $\mathrm{Ln}^{3+}$ ions relating to the valance band of SAS materials has been constructed by using the data of fluorescent properties of $\mathrm{Ce}^{3+}$ and $\mathrm{Eu}^{3+}$ ions. The energy of $4 \mathrm{f} \rightarrow 5 \mathrm{~d}$ transitions of $\mathrm{Eu}^{2+}$ ions that was predicted from the energy level scheme matches well with the observed experimental energy.
\end{abstract}

Keywords: Charge transfer, lanthanide, cerium, europium, energy levels

\section{Introduction}

The last decade has brought along the increased interests in new solid state luminescent materials, among which, lanthanides ( $\mathrm{Ln}$ ) doped strontium aluminosilicate, $\mathrm{Sr}_{2} \mathrm{Al}_{2} \mathrm{SiO}_{7}(\mathrm{SAS})$, phosphors have attracted the attention of scientists in recent years because of their advantage as highly thermal stable

\footnotetext{
* Corresponding author.

Email address: hovantuyen@gmail.com
}

https//doi.org/ 10.25073/2588-1124/vnumap.4594 
[1], steady crystalline structure [2]. In some recent studies, $\mathrm{Eu}^{2+}$-doped SAS materials have been synthesized to obtain green emission phosphor [3]; long persistent luminescence and thermoluminescence properties of $\mathrm{Eu}$ and $\mathrm{Ln}^{3+}\left(\mathrm{Dy}^{3+}, \mathrm{Ce}^{3+}, \mathrm{Tm}^{3+}\right)$ co-doped into SAS host materials have also reported [4-8]; Energy transfer between $\mathrm{Ce}^{3+}$ and $\mathrm{Dy}^{3+}, \mathrm{Eu}^{3+}$ ions as well as the concentration quenching of $\mathrm{Ce}^{3+}$ in SAS materials have been studied [9-11]. Besides that, the fabrication method for SAS phosphors has been studied and reported in several papers $[12,13]$ and some other studies have focused on the controllable photoluminescence or thermal stablility of the prepared materials $[1,14]$.

It is known that, in different host lattices, the emission color and the thermal stability of luminescence materials are very various and these aspects are related to the position of energy levels of lanthanide ions in host lattice [15-17]. From information of the energy level position of a Ln ion in a compound, it will predict some luminescent and thermoluminescence properties of Ln ions in a compound. As presented above, many Ln ions were activated in SAS lattice to estimate the performance of their luminescent characteristic. However, there has been no literature until now presenting the position of Ln ions in the SAS host lattice. Therefore, in this study, the host referred binding energy (HRBE) diagram for all lanthanide ions in the SAS host lattice will be constructed and used to explain the nature emission of Ln ions doping this host material.

\section{Experimental}

The sample $\mathrm{Sr}_{2} \mathrm{Al}_{2} \mathrm{SiO}_{7}: \mathrm{Ce}^{3+}(1 \mathrm{~mol} \%)$ and $\mathrm{Sr}_{2} \mathrm{Al}_{2} \mathrm{SiO}_{7}: \mathrm{Eu}^{3+}(1 \mathrm{~mol} \%)$ were fabricated by solid-state reaction method at high temperature. Firstly, the raw materials, $\mathrm{SrCO}_{3}(\mathrm{AR}), \mathrm{Al}_{2} \mathrm{O}_{3}(\mathrm{AR}), \mathrm{SiO}_{2}$ (Sigma), $\mathrm{Ce}_{2} \mathrm{O}_{3}$ (Merck), and $\mathrm{Eu}_{2} \mathrm{O}_{3}$ (Merck) were weighted according to the nominal composition, mixed homogeneously and milled thoroughly using an agate pestle and mortar to achieve a uniform mixture. A small amount of $\mathrm{B}_{2} \mathrm{O}_{3}$ was added during mixing process to serve as a flux to promote the formation of crystal structure. After that, this mixture was ground and calcined at $1250^{\circ} \mathrm{C}$ for $2 \mathrm{~h}$ in air. To obtain the $\mathrm{Sr}_{2} \mathrm{Al}_{2} \mathrm{SiO}_{7}: \mathrm{Eu}^{2+}$ phosphor, the obtained $\mathrm{Sr}_{2} \mathrm{Al}_{2} \mathrm{SiO}_{7}: \mathrm{Eu}^{3+}$ sample after calcination at $1250^{\circ} \mathrm{C}$ was further annealed in the reduction atmosphere at $900^{\circ} \mathrm{C}$ for $1 \mathrm{~h}$. The obtained product was finally ground into powder to analyze phase compositions and luminescent property.

Structural characteristic of the prepared samples was investigated by X-ray diffraction (XRD) patterns using an X-ray diffractometer D8-Advance (Bruker, Germany). The surface homology of the prepared samples was examined with a scanning electron microscope (SEM) (Jeol 6490, JED 2300; Japan). Photoluminescence (PL) and photoluminescence excitation (PLE) spectra were taken out by a spectrophotometer (FL3-22, Horiba Jobin-Yvon).

\section{Results and Discussion}

\subsection{X-ray Diffraction and SEM Image}

$\mathrm{X}$-ray diffraction (XRD) patterns of the as-prepared samples $\mathrm{Sr}_{2} \mathrm{Al}_{2} \mathrm{SiO}_{7}: \mathrm{Ce}^{3+}$ (SASC) and $\mathrm{Sr}_{2} \mathrm{Al}_{2} \mathrm{SiO}_{7}: \mathrm{Eu}^{3+}(\mathrm{SASE})$ were figured out by using $\mathrm{Cu} \mathrm{K}$-alpha $(0.154 \mathrm{~nm})$ radiation and their results are presented in Figure 1. The strong diffraction peaks are in accordance with those of tetragonal phase (JCPDS: 38-1333). No impure phases were found indicating that the single phase $\mathrm{Sr}_{2} \mathrm{Al}_{2} \mathrm{SiO}_{7}$ was successfully synthesized with used technology conditions. The crystal structure of the prepared materials $\mathrm{Sr}_{2} \mathrm{Al}_{2} \mathrm{SiO}_{7}$ can be refined to be tetragonal, space group $\mathrm{P} 421 \mathrm{~m}$ with lattice parameters $(\mathrm{a}=7.820 \AA$, $\mathrm{b}=7.820 \AA$, and $\mathrm{c}=5.264 \AA$ ). SEM images of two prepared samples presented Figure 2 are similar in 
shape and size. It can be seen that the particles tend to agglomerate, forming clusters with irregular shapes and a large size.

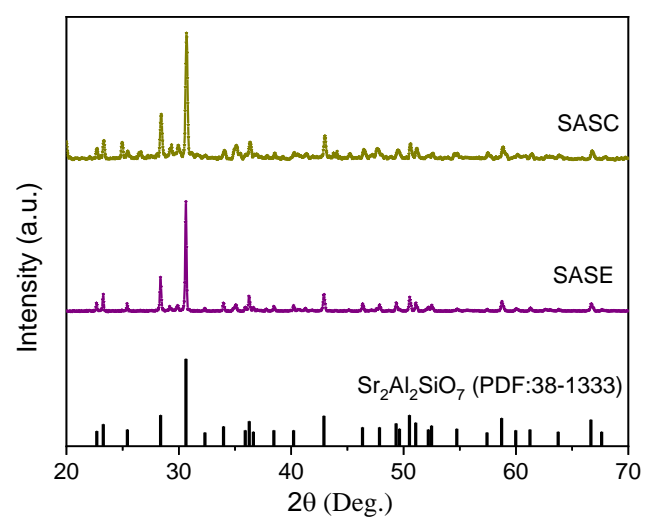

Figure 1. XRD patterns of SASC and SASE samples.
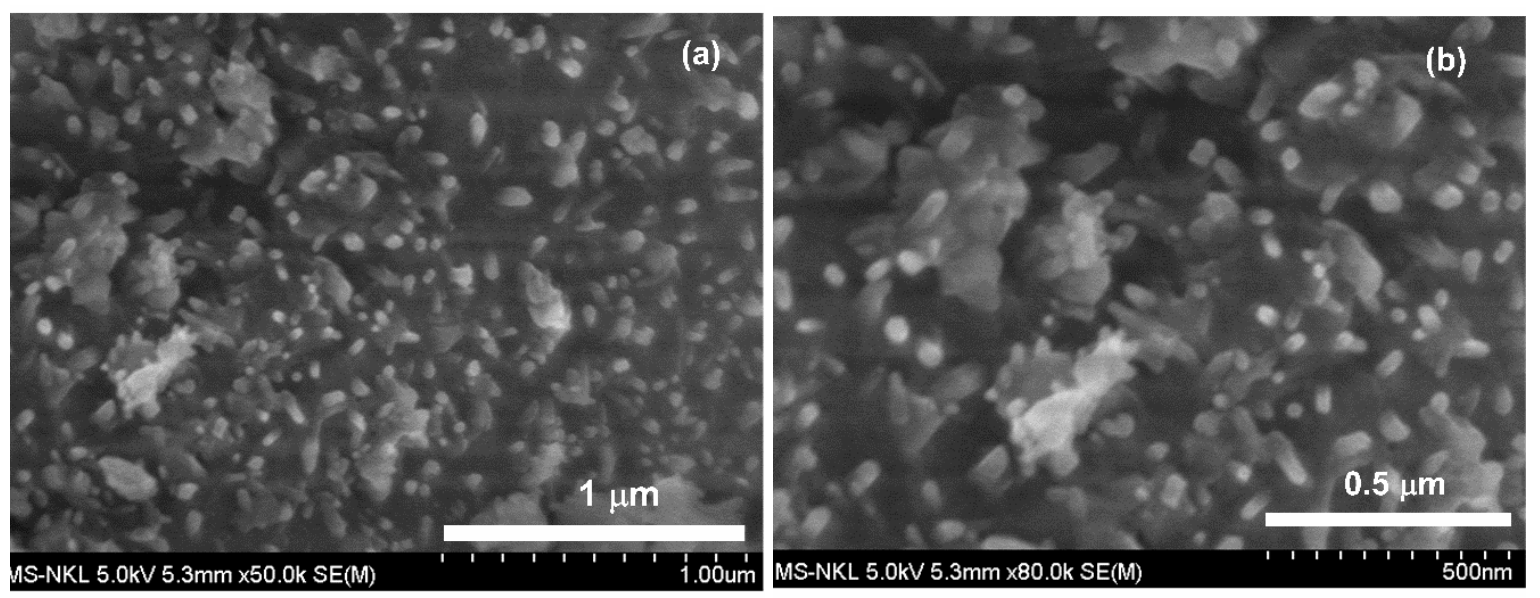

Figure 2. SEM images of SASC (a) and SASE (b) samples

\subsection{Luminescent Properties of SASC and SASE Phosphors}

Figure 3 illustrates photoluminescence excitation (PLE) and photoluminescence (PL) spectra of SASC sample at room temperature. The PL spectrum was measured under excitation wavelength of 334 $\mathrm{nm}$ and it shows a broad-band emission centered at $400 \mathrm{~nm}$, which is caused by the $5 \mathrm{~d} \rightarrow 4 \mathrm{f}$ transition of $\mathrm{Ce}^{3+}$ ions. This emission band also shows asymmetry that results from the spin-orbit coupling into two levels $\left({ }^{2} \mathrm{~F}_{5 / 2}\right.$ and $\left.{ }^{2} \mathrm{~F}_{7 / 2}\right)$ of the $4 \mathrm{f}$ ground state of the $\mathrm{Ce}^{3+}$ ions $[18,19]$, and it can be deconvoluted into two Gaussians peaking at $396 \mathrm{~nm}(3.13 \mathrm{eV})$ and $430 \mathrm{~nm}(2.88 \mathrm{eV})$. The energy difference between the spin-orbit spliting of the $4 \mathrm{f}$ ground state in the SASC sample is about $1997 \mathrm{~cm}^{-1}$, which is in good agreement with the general value $2000 \mathrm{~cm}^{-1}[19,20]$. 


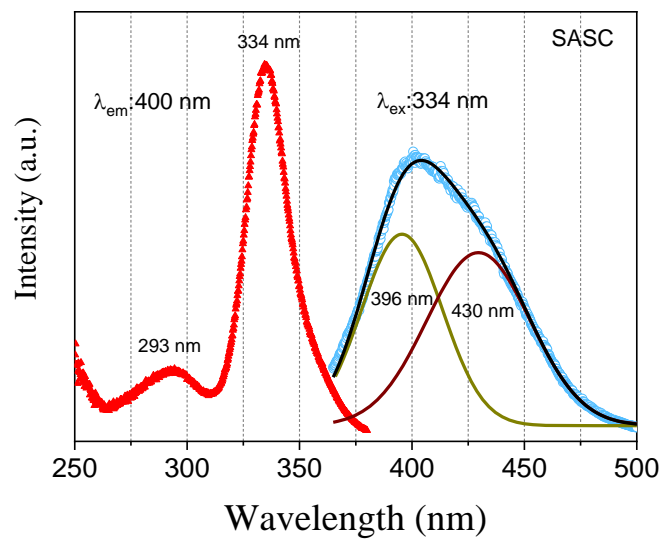

Figure 3. PLE and PL spectra of SASC sample.

The PLE spectrum of SASC sample recorded at the emission wavelenght of $400 \mathrm{~nm}$ shows two broad bands centered at $334 \mathrm{~nm}$ and $293 \mathrm{~nm}$, which are the excited transitions from the $4 \mathrm{f}$ ground state to the $5 \mathrm{~d}_{\mathrm{J}}$ excited states of the $\mathrm{Ce}^{3+}$ ions. In which the broad band peaking at $334 \mathrm{~nm}(3.71 \mathrm{eV})$ is identified to the lowest $4 \mathrm{f}^{1} \rightarrow 5 \mathrm{~d}^{1}$ excitation transition (arrow 1 in Figure 5) of the $\mathrm{Ce}^{3+}$ ions in the SAS host lattice, and this energy is one of the parameters to construct the energy level scheme of the lanthanide levels in SAS host lattice in the next section.

PL spectrum under the excitation wavelength of $393 \mathrm{~nm}$ and PLE spectrum recorded at emission wavelength of $617 \mathrm{~nm}$ of SASE sample at room temperature are presented in Figure 4. The PL spectrum includes five strong peaks locating at $576 \mathrm{~nm}\left({ }^{5} \mathrm{D}_{0} \rightarrow{ }^{7} \mathrm{~F}_{0}\right), 586 \mathrm{~nm}\left({ }^{5} \mathrm{D}_{0} \rightarrow{ }^{7} \mathrm{~F}_{1}\right), 617 \mathrm{~nm}\left({ }^{5} \mathrm{D}_{0} \rightarrow{ }^{7} \mathrm{~F}_{2}\right), 655$ $\mathrm{nm}\left({ }^{5} \mathrm{D}_{0} \rightarrow{ }^{7} \mathrm{~F}_{3}\right)$, and $700 \mathrm{~nm}\left({ }^{5} \mathrm{D}_{0} \rightarrow{ }^{7} \mathrm{~F}_{4}\right)$. The sample exhibits the red emission with the main contribution of the ${ }^{5} \mathrm{D}_{0} \rightarrow{ }^{7} \mathrm{~F}_{2}$ transition. The PLE spectrum recorded in the $240-550 \mathrm{~nm}$ region has a broad band at 240-325 nm and many sharp peaks in the $325-550 \mathrm{~nm}$ region. The intense sharp peaks include the ${ }^{7} \mathrm{~F}_{0 / 1} \rightarrow{ }^{5} \mathrm{D}_{1}$ transitions $(524 \mathrm{~nm})$, the ${ }^{7} \mathrm{~F}_{0} \rightarrow{ }^{5} \mathrm{D}_{2}$ transition $(462 \mathrm{~nm})$, the ${ }^{7} \mathrm{~F}_{0} \rightarrow{ }^{5} \mathrm{~L}_{6}$ transition $(393 \mathrm{~nm})$, and the ${ }^{7} \mathrm{~F}_{0} \rightarrow{ }^{5} \mathrm{D}_{4}$ transition $(361 \mathrm{~nm})$, which correspond to the excited transitions of electrons from the ${ }^{7} \mathrm{~F}_{\mathrm{J}}$ levels to the excited levels of $\mathrm{Eu}^{3+}$ ions in SAS compound, while the broad band with maximum at 264 $\mathrm{nm}$ is the charge transfer (CT) transition between the $\mathrm{Eu}^{3+}$ ions and host lattice. Energy of this $\mathrm{CT}$ band $\left(E^{\mathrm{CT}}\right)$ is $4.70 \mathrm{eV}$; it is also used to construct the energy level diagram of lanthanide ions in SAS host lattice in Section 3.3.

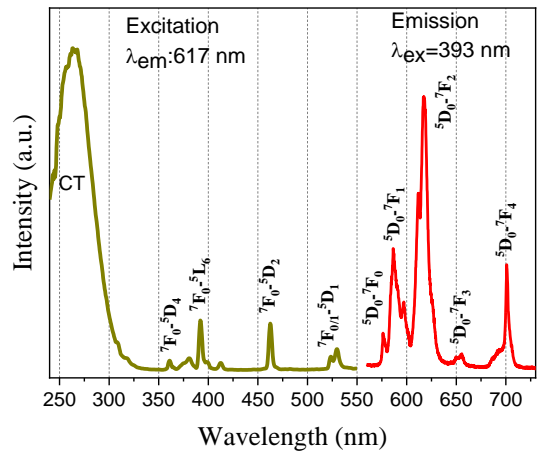

Figure 4. PLE and PL of SASE sample. 


\subsection{Construction of the Energy Level Scheme of Lanthanides in the SAS Host Lattice}

In this section, the host referred binding energy (HRBE) diagram for all lanthanide ions in the SAS host lattice will be constructed by using energies of the lowest $4 \mathrm{f}-5 \mathrm{~d}$ transition of $\mathrm{Ce}^{3+}$ ions and the charge transfer of $\mathrm{Eu}^{3+}$ ions in this material.

Firstly, the lowest $4 \mathrm{f}-5 \mathrm{~d}$ energies $E_{\mathrm{fd}}\left(\mathrm{Ln}^{3+/ 2+}\right.$, SAS $)$ of the corresponding $\mathrm{Ln}^{3+/ 2+}$ ions in SAS host lattice are predicted from the data of PLE spectrum of $\mathrm{Ce}^{3+}$ ions in SASC sample. It is known that in $\mathrm{Ln}^{3+/ 2+}$ ions doped SAS material, $E_{\mathrm{fd}}\left(\mathrm{Ln}^{3+/ 2+}, \mathrm{SAS}\right)$, energies are shifted toward the low energy (redshift) in the comparison with those of corresponding $\mathrm{Ln}^{3+/ 2+}$ free ions. This redshift energy $\mathrm{D}\left(\mathrm{Ln}^{3+/ 2+}, \mathrm{SAS}\right)$ does not change for all lanthanide ions in the same compound but it is affected by the compound. The redshift value relates to the $E_{\mathrm{fd}}\left(\mathrm{Ln}^{3+/ 2+}, \mathrm{SAS}\right)$ as in the following equation [21, 22]:

$$
E_{\mathrm{fd}}\left(\mathrm{Ln}^{3+/ 2+}, \mathrm{SAS}\right)=E_{\mathrm{fd}}\left(\mathrm{Ln}^{3+/ 2+}, \text { free }\right)-D\left(\mathrm{Ln}^{3+/ 2+}, \mathrm{SAS}\right)
$$

where $E_{\mathrm{fd}}\left(\mathrm{Ln}^{3+/ 2+}\right.$, free $)$ is the energy of the lowest $4 \mathrm{f} \rightarrow 5 \mathrm{~d}$ excited state of free $\mathrm{Ln}^{3+/ 2+}$ ions and its values for all lanthanides have been found in the literature [23]. In Section 3.2, $E_{\mathrm{fd}}\left(\mathrm{Ce}^{3+}, \mathrm{SAS}\right)$ is found to be $3.71 \mathrm{eV}(334 \mathrm{~nm})$ from PLE spectrum of SASC sample in Figure 3. Therefore, $D\left(\mathrm{Ln}^{3+}, \mathrm{SAS}\right)$ value is determined by using the known $E_{\mathrm{fd}}\left(\mathrm{Ce}^{3+}, \mathrm{SAS}\right)$ and $E_{\mathrm{fd}}\left(\mathrm{Ce}^{3+}\right.$, free $)$ values, and $D\left(\mathrm{Ln}^{3+}, \mathrm{SAS}\right)$ is found to be $2.41 \mathrm{eV}$. From this energy, we can predict the $E_{\mathrm{fd}}\left(\mathrm{Ln}^{3+}, \mathrm{SAS}\right)$ energies for all $\mathrm{Ln}^{3+}$ ions in the SAS host lattice by using Equation 1, and the results are shown in Column 4, Table 1. Besides that, the redshift energies of $\mathrm{Ln}^{3+}$ and $\mathrm{Ln}^{2+}$ relate to each other as below [21]:

$$
D\left(\mathrm{Ln}^{2+}, \mathrm{SAS}\right)=0.64 D\left(\mathrm{Ln}^{3+}, \mathrm{SAS}\right)-0.233 \mathrm{eV}
$$

Using Equation 2, $D\left(\mathrm{Ln}^{2+}, \mathrm{SAS}\right)$ value reaches $1.31 \mathrm{eV}$ and it is used to estimate $E_{\mathrm{fd}}\left(\mathrm{Ln}^{2+}, \mathrm{SAS}\right)$ energies for all $\mathrm{Ln}^{2+}$ ions in SAS compound via Equation 1. The obtained $E_{\mathrm{fd}}\left(\mathrm{Ln}^{2+}, \mathrm{SAS}\right)$ energies are listed in Column 7, Table 1.

Secondly, the energy level positions of the $4 \mathrm{f}$ states of $\mathrm{Ln}^{3+}$ ions compared to the top of the valence band of SAS compound can be obtained through the charge transfer energy of $\mathrm{Eu}^{3+}$ in the same compound. The energy needed to transfer an electron from the valence band to a trivalent lanthanide impurity in a compound is called the charge transfer energy $E^{\mathrm{CT}}$. The $E^{\mathrm{CT}}$ value of a trivalent lanthanide ion provides information on the locations of the ground state of the corresponding divalent lanthanide ion relative to the top of the valence band in the same compound, $E^{\mathrm{CT}}\left(\mathrm{Ln}^{3+}, \mathrm{SAS}\right)=E_{\mathrm{Vf}}\left(\mathrm{Ln}^{2+}, \mathrm{SAS}\right)[17$, $22,24]$. Among lanthanide ions, $\mathrm{Eu}^{3+}$ ion is often used to calculate the $E^{\mathrm{CT}}$ value because it has the low charge transfer energy and therefore the $E^{\mathrm{CT}}$ value is easy determined from its excitation spectrum. From PLE spectrum of SASE in Figure 4, $E^{\mathrm{CT}}\left(\mathrm{Eu}^{3+}, \mathrm{SAS}\right)$ is found of $4.70 \mathrm{eV}$, hence we obtain the $E_{\mathrm{vf}}\left(\mathrm{Eu}^{2+}\right.$, $\mathrm{SAS})=4.70 \mathrm{eV}$ (arrow 2 in Figure 5). This energy is used to predict $E_{\mathrm{Vf}}\left(\operatorname{Ln}^{2+}, \mathrm{CAS}\right)$ for all other divalent lanthanides in the SAS host lattice by using the known energy difference $\Delta E_{\mathrm{Vf}}\left(\operatorname{Ln}^{2+}, \mathrm{Eu}^{2+}\right)$ in ref. [23] and the results are listed in Column 3, Table 1. For trivalent lanthanides, energy $E_{\mathrm{Vf}}\left(\operatorname{Ln}^{3+}\right)$ can be determined via the $E^{\mathrm{CT}}$ energy of tetravalent lanthanide $\left(\mathrm{Ln}^{4+}\right)$ ions. However, there is too little available information on such transitions of the $\mathrm{Ln}^{4+}$ ions in literature. Instead, $E_{\mathrm{Vf}}\left(\mathrm{Ln}^{3+}\right)$ can be evaluated by using the correlation energy $U(6)$, which is known as the energy difference between the ground state energy of $\mathrm{Eu}^{2+}$ and that of $\mathrm{Eu}^{3+}$ ions in the same compound [21].

$$
U(6, \mathrm{SAS})=E_{\mathrm{Vf}}\left(\mathrm{Eu}^{2+}, \mathrm{SAS}\right)-E_{\mathrm{Vf}}\left(\mathrm{Eu}^{3+}, \mathrm{SAS}\right)
$$

Studies of Dorenbos show that $U(6)$ reaches various values depending the host lattice and it ranges from 6.4 to $7.2 \mathrm{eV}$ in oxide [22]. Some oxide materials get $U(6)$ with the medium value, such as $\mathrm{Y}_{3} \mathrm{Al}_{5} \mathrm{O}_{12}$ $(6.75 \mathrm{eV})$ [22] and $\mathrm{Gd}_{5} \mathrm{Si}_{3} \mathrm{O}_{12} \mathrm{~N}(6.80 \mathrm{eV})$ [25]. $\mathrm{Sr}_{2} \mathrm{Al}_{2} \mathrm{SiO}_{7}$ compound is also an oxide host containing silicate, therefore $U(6, \mathrm{SAS})$ is chosen about $6.80 \mathrm{eV}$. Using Equation $3, E_{\mathrm{Vf}}\left(\mathrm{Eu}^{3+}, \mathrm{SAS}\right)$ is found to be $-2.10 \mathrm{eV}$. It can now predict $E_{\mathrm{Vf}}\left(\mathrm{Ln}^{3+}, \mathrm{SAS}\right)$ energies for all trivalent lanthanides in SAS host lattice by 
using the known $E_{\mathrm{Vf}}\left(\mathrm{Eu}^{3+}\right.$, SAS) value and the energy difference between the $4 \mathrm{f}$ ground state of $\mathrm{Ln}^{3+}$ ions with that of $\mathrm{Eu}^{3+} \Delta E_{\mathrm{vf}}\left(\mathrm{Ln}^{3+}, \mathrm{Eu}^{3+}\right)$ given in [23], the results are listed in Column 6, able 1 .

Table 1. Charge transfer energies $\left(E^{C T} \equiv E_{\mathrm{Vf}}\right)$, the lowest $4 \mathrm{f} \rightarrow 5 \mathrm{~d}$ energies $\left(E_{\mathrm{fd}}\right)$ and energies from $5 \mathrm{~d}$ state to the top of the valence band $\left(E_{5 d}\right)$ for $\mathrm{Ln}^{3+}$ and $\mathrm{Ln}^{2+}$ ions in SAS host lattice (all energies are in $\mathrm{eV}$ ). $n$ is the number of electrons in the $4 \mathrm{f}$ configuration in trivalent lanthanides

\begin{tabular}{|l|l|l|l|l|l|l|l|}
\hline $\mathrm{Ln}$ & $n$ & $E_{\mathrm{Vf}}\left(\mathrm{Ln}^{2+}, \mathrm{SAS}\right)$ & $E_{\mathrm{fd}}\left(\mathrm{Ln}^{2+}, \mathrm{SAS}\right)$ & $E_{5 \mathrm{~d}}\left(\mathrm{Ln}^{2+}, \mathrm{SAS}\right)$ & $E_{\mathrm{Vf}}\left(\mathrm{Ln}^{3+}, \mathrm{SAS}\right)$ & $E_{\mathrm{fd}}\left(\mathrm{Ln}^{3+}, \mathrm{SAS}\right)$ & $E_{5 \mathrm{~d}}\left(\mathrm{Ln}^{3+}, \mathrm{SAS}\right)$ \\
\hline $\mathrm{La}$ & 0 & 10.31 & -2.25 & 8.06 & $\ldots$ & $\ldots$ & $\ldots$ \\
\hline $\mathrm{Ce}$ & 1 & 8.83 & -0.93 & 7.90 & 3.14 & 3.71 & 6.85 \\
\hline $\mathrm{Pr}$ & 2 & 7.57 & 0.28 & 7.85 & 1.29 & 5.22 & 6.51 \\
\hline $\mathrm{Nd}$ & 3 & 7.22 & 0.56 & 7.78 & -0.20 & 6.51 & 6.31 \\
\hline $\mathrm{Pm}$ & 4 & 7.04 & 0.65 & 7.69 & -0.64 & 6.83 & 6.19 \\
\hline $\mathrm{Sm}$ & 5 & 5.95 & 1.69 & 7.64 & -0.83 & 6.93 & 6.10 \\
\hline $\mathrm{Eu}$ & 6 & 4.70 & 2.91 & 7.61 & -2.10 & 8.09 & 5.99 \\
\hline $\mathrm{Gd}$ & 7 & 9.26 & -1.51 & 7.75 & -3.44 & 9.39 & 5.95 \\
\hline $\mathrm{Tb}$ & 8 & 7.91 & -0.12 & 7.79 & 1.47 & 5.37 & 6.84 \\
\hline $\mathrm{Dy}$ & 9 & 6.97 & 0.86 & 7.83 & 0.05 & 6.84 & 6.89 \\
\hline $\mathrm{Ho}$ & 10 & 6.70 & 0.94 & 7.64 & -1.05 & 7.69 & 6.64 \\
\hline $\mathrm{Er}$ & 11 & 7.28 & 0.81 & 8.09 & -0.98 & 7.45 & 6.47 \\
\hline $\mathrm{Tm}$ & 12 & 6.42 & 1.64 & 8.06 & -0.82 & 7.34 & 6.52 \\
\hline $\mathrm{Yb}$ & 13 & 5.13 & 2.91 & 8.04 & -1.87 & 8.48 & 6.61 \\
\hline $\mathrm{Lu}$ & 14 & $\ldots$ & $\ldots$ & $\ldots$ & -3.11 & 9.85 & 6.74 \\
\hline
\end{tabular}

After $E_{\mathrm{Vf}}\left(\mathrm{Ln}^{3+/ 2+}, \mathrm{SAS}\right)$ and $E_{\mathrm{fd}}\left(\mathrm{Ln}^{3+/ 2+}, \mathrm{SAS}\right)$ are determined, the position of the $5 \mathrm{~d}$ state for all trivalent and divalent lanthanides in SAS host lattice is found by the following expression:

$$
E_{5 \mathrm{~d}}\left(\mathrm{Ln}^{3+/ 2+}, \mathrm{SAS}\right)=E_{\mathrm{Vf}}\left(\operatorname{Ln}^{3+/ 2+}, \mathrm{SAS}\right)+E_{\mathrm{fd}}\left(\operatorname{Ln}^{3+/ 2+}, \mathrm{SAS}\right)
$$

The results of $E_{5 \mathrm{~d}}$ for all divalent and trivalent lanthanides are presented in Columns 5 and 8, Table 1, respectively. Using $E_{\mathrm{Vf}}, E_{5 \mathrm{~d}}$ in Table 1 and band gap $~ 5.3 \mathrm{eV}$ [26], we can construct the HRBE diagram for all lanthanide ions in the SAS compound as in Figure 5.

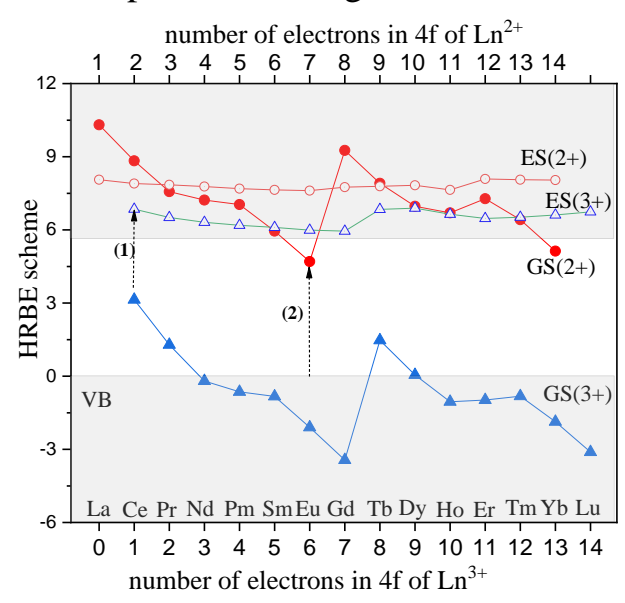

Figure 5. The HRBE scheme of $\mathrm{Ln}^{2+}$ and $\mathrm{Ln}^{3+}$ ions in SAS host lattice.

To check the correctness of the obtained energy diagram, PL and PLE spectra of $\mathrm{Eu}^{2+}$ ions in SAS have been measured to compare to the predicted data from HRBE diagram. The PL spectrum of $\mathrm{Eu}^{2+}$ 
ions under the excited radiation of $424 \mathrm{~nm}$, shown in Figure 6 (a), has a broad band emission from 450 $\mathrm{nm}$ to $650 \mathrm{~nm}$ corresponding to the $5 \mathrm{~d}-4 \mathrm{f}$ transition of $\mathrm{Eu}^{2+}$ ions in SAS host lattice. The PLE spectrum recorded at emission wavelength of $510 \mathrm{~nm}$ is presented in Figure 6 (b). It can be seen that the excitation spectrum is a broad band in the 260 - $460 \mathrm{~nm}$ region, which is contituted of four $4 \mathrm{f}-5 \mathrm{~d}$ excited transitions located $293 \mathrm{~nm}, 317 \mathrm{~nm}, 363 \mathrm{~nm}$ and $424 \mathrm{~nm}$, in which, the excitation peak at $424 \mathrm{~nm}(2.924 \mathrm{eV})$ is the lowest $4 \mathrm{f}-5 \mathrm{~d}$ excited transition of $\mathrm{Eu}^{2+}$ ions in SAS material and coincides with the result of the excitation spectra of $\mathrm{Eu}^{2+}$ ions in ref. [5], which shows the lowest $4 \mathrm{f}-5 \mathrm{~d}$ of $\mathrm{Eu}^{2+}$ ions is about $425 \mathrm{~nm}$. From the HRBE diagram in Figure 5 and results in Table 1, the predicted lowest $4 \mathrm{f}-5 \mathrm{~d} \mathrm{of} \mathrm{Eu}^{2+}$ ions doped SAS compound is around $2.91 \mathrm{eV}$ and this energy coincides well with the experimental energy in Figure 6 (b) with a slight difference of $0.5 \%$. This indicates that the obtained energy scheme can be used to predict the energy levels positions of lanthanides doped SAS host lattice. Besides, the predicted value of the $4 \mathrm{f}-5 \mathrm{~d}$ excited transition of $\mathrm{Eu}^{2+}$ ions in Table 1 is $2.91 \mathrm{eV}$, which coincides with the $5 \mathrm{~d}-4 \mathrm{f}$ emission energy of $\mathrm{Ce}^{3+}$ ions (2.88-3.13 eV) in Figure 3. Therefore, the energy transfer phenomenon can occur between two ions when they codope SAS host lattice; this prediction has also been confirmed in [5].
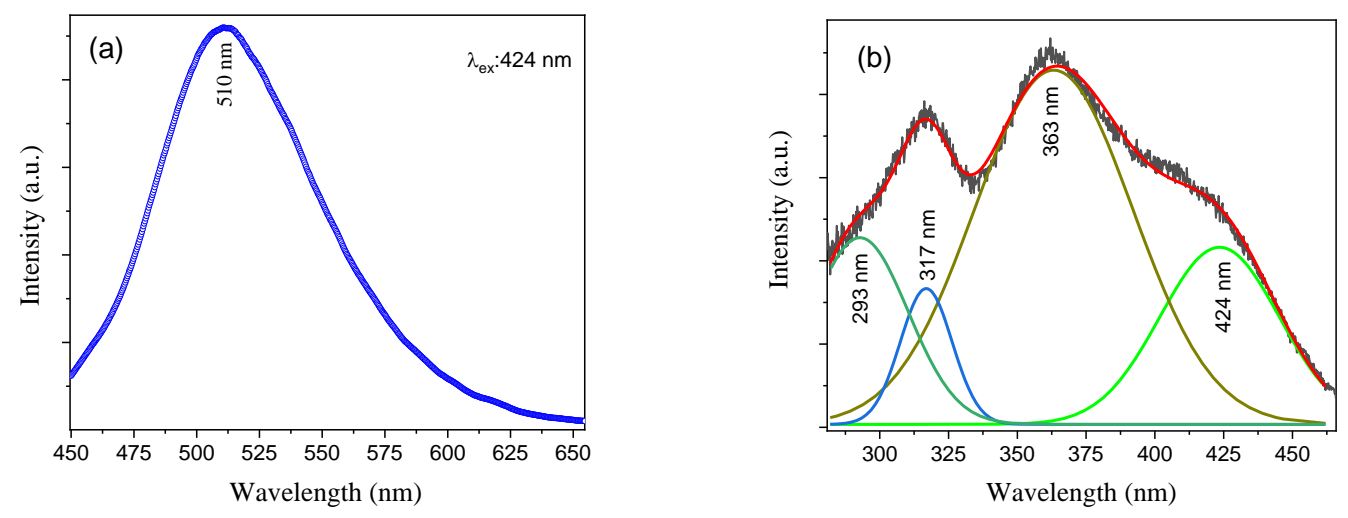

Figure 6. PL (a) and PLE (b) spectra of $\mathrm{Eu}^{2+}$ ions doped SAS material.

\section{Conclusion}

The structure and luminescence properties of $\mathrm{Sr}_{2} \mathrm{Al}_{2} \mathrm{SiO}_{7}$ doped with $\mathrm{Eu}^{3+}$ and $\mathrm{Ce}^{3+}$ ions $(1 \mathrm{~mol} \%)$ have been studied through X-ray diffraction and fluorescence technique. The energy level positions of $\mathrm{Ln}^{2+}$ and $\mathrm{Ln}^{3+}$ relative to the valence band in $\mathrm{Sr}_{2} \mathrm{Al}_{2} \mathrm{SiO}_{7}$ host lattice were determined by using data of photoluminescence excitation spectra of $\mathrm{Ce}^{3+}$ and $\mathrm{Eu}^{3+}$ ions doped $\mathrm{Sr}_{2} \mathrm{Al}_{2} \mathrm{SiO}_{7}$ compound, and the predicted energies from the energy levels scheme were in good agreement with experimental energies.

\section{Acknowledgments}

This research is funded by Vietnam National Foundation for Science and Technology Development (NAFOSTED) under Grant 103.03-2018.323. 


\section{References}

[1] H. Zou, D. Peng, Z. Chu, X. Wang, Y. Li, X. Yao, A Highly Thermal Stable and Waterproof Red Phosphor: $\operatorname{Pr}^{3+}$ doped $\mathrm{Sr}_{2} \mathrm{Al}_{2} \mathrm{SiO}_{7}$, J. Mater. Sci, Vol. 48, No. 22, 2013, pp. 7981-7985, https://doi.org/10.1007/s10853-013-7609$\mathrm{X}$.

[2] J. Wu, B. Yan, Sol-gel Synthesis of Green-Luminescence Microcrystalline Phosphors $\mathrm{Sr}_{\mathrm{x}} \mathrm{Ca}_{2-\mathrm{x}} \mathrm{Al}_{2} \mathrm{SiO}_{7}: \mathrm{yTb}^{3+}, \mathrm{zCe}^{3+}$ by Hybrid Precursors, Colloids. Surf. A: Physicochem. Eng. Asp, Vol. 297, No. 3, 2007, pp. 253-257, https://doi.org/10.1016/j.colsurfa.2006.10.052.

[3] F. C. Lu, L. J. Bai, W. Dang, Z. P. Yang, P. Lin, Structure and Photoluminescence of $\mathrm{Eu}^{2+} \mathrm{Doped}_{2} \mathrm{Al}_{2} \mathrm{SiO}_{7} \mathrm{Cyan}_{-}$ green Emitting Phosphors, ECS J. Solid State Sci. Technol, Vol. 4, No. 2, 2014, pp. R27-R30, https://doi.org/10.1149/2.0151502jss.

[4] Y. Ding, Y. Zhang, Z. Wang, W. Li, D. Mao, H. Han, C. Chang, Photoluminescence of Eu Single Doped and Eu/Dy Codoped $\mathrm{Sr}_{2} \mathrm{Al}_{2} \mathrm{SiO}_{7}$ Phosphors with Long Persistence, J. Lumin, Vol. 129, No. 3, 2009, pp. 294-299, https://doi.org/10.1016/j.jlumin.2008.10.009.

[5] G. Li, M. Li, L. Li, H. Yu, H. Zou, L. Zou, S. Gan, X. Xu, Luminescent Properties of $\mathrm{Sr}_{2} \mathrm{Al}_{2} \mathrm{SiO}_{7}: \mathrm{Ce}^{3+}, \mathrm{Eu}^{2+}$ Phosphors for Near UV-excited White Light-emitting Diodes, Mater. Lett, Vol. 65, No. 23, 2011, pp. 3418-3420, https://doi.org/10.1016/j.matlet.2011.07.050.

[6] A. Jadhaw, V. D. Sonwane, A. S. Gour, P. Jha, Thermoluminescence Properties of Eu-doped and Eu/Dy-codoped $\mathrm{Sr}_{2} \mathrm{Al}_{2} \mathrm{SiO}_{7}$ Phosphors, Luminescence, Vol. 32, No. 7, 2017, pp. 1349-1353, https://doi.org/10.1002/bio.3331.

[7] H. Y. Jiao, Y. H. Wang, Intense Red Phosphors for Near-ultraviolet Light-emitting Diodes, Appl. Phys. B, Vol. 98, No. 2, 2009, pp. 423-427, https://doi.org/10.1007/s00340-009-3708-4.

[8] I. P. Sahu, D. P. Bisen, N. Brahme, R. K. Tamrakar, Studies on the Luminescence Properties of Europium Doped Strontium Alumino-silicate Phosphors by Solid State Reaction Method, J. Mater. Sci.: Mater. Electron, Vol. 26, No. 12, 2015, pp. 10075-10086, https://doi.org/10.1007/s10854-015-3691-y.

[9] Y. Gong, Y. Wang, Y. Li, X. Xu, Ce ${ }^{3+}, \mathrm{Dy}^{3+}$ Co-doped White-light Long-lasting Phosphor: $\mathrm{Sr}_{2} \mathrm{Al}_{2} \mathrm{SiO}_{7}$ Through Energy Transfer, J. Electrochem. Soc, Vol. 157, No. 6, 2010, pp. J208-J211, https://doi.org/10.1149/1.3371488.

[10] M. Kolte, V. B. Pawade, S. J. Dhoble, Quenching and Dipole-dipole Interactions in $\mathrm{Sr}_{2} \mathrm{Al}_{2} \mathrm{SiO}_{7}: \mathrm{Ce}^{3+} \mathrm{Host}_{\text {Lattice, }}$ Appl. Phys. A, Vol. 122, No.2, 2016, pp. 59:1-59:5, https://doi.org/10.1007/s00339-015-9579-0.

[11] H. V. Tuyen, D. T. Tien, N. M. Son, D. V. Phan, Judd-Ofelt Parameters of $\mathrm{Eu}^{3+}$ and Energy Transfer of $\mathrm{Ce}^{3+} / \mathrm{Eu}^{3+}$ in $\mathrm{Sr}_{2} \mathrm{Al}_{2} \mathrm{SiO}_{7}$ Materials, J. Electron. Mater, Vol. 48, No.12, 2019, pp. 7799-7805, https://doi.org/10.1007/s11664019-07608-6.

[12] W. Pan, G. Ning, Y. Lin, X. Yang, Sol-gel Processed $\mathrm{Ce}^{3+}, \mathrm{Tb}^{3+}$ Codoped White Emitting Phosphors in $\mathrm{Sr}_{2} \mathrm{Al}_{2} \mathrm{SiO}_{7}$, J. Rare Earth, Vol. 26, No. 2, 2008, pp. 207-210, https://doi.org/10.1016/S1002-0721(08)60066-6.

[13] W. Zhou, X. Ma, M. Zhang, Y. Luo, Z. Xia, Effect of Different RE Dopants on Phosphorescence Properties of $\mathrm{Sr}_{2} \mathrm{Al}_{2} \mathrm{SiO}_{7}: \mathrm{Eu}^{2+}$ Phosphors, J. Rare Earth, Vol. 33, No. 7, 2015, pp. 700-705, https://doi.org/10.1016/S10020721(14)60473-7.

[14] P. Zhang, Z. Lu, Q. Yuan, Q. Hou, T. D. Golden, X. Ren, L. Weng, H. Wang, A Novel Composite Phosphor Via One-pot Synthesis: Single Matrix with Controllable Luminescence, Mater. Chem. Phys, Vol. 134, No. 3, 2012, pp. 1190-1196, https://doi.org/10.1016/j.matchemphys.2012.04.020.

[15] T. Shalapska, P. Dorenbos, A. Gektin, G. Stryganyuk, A. Voloshinovskii, Luminescence Spectroscopy and Energy Level Location of Lanthanide Ions Doped in $\mathrm{La}\left(\mathrm{PO}_{3}\right)_{3}$, J. Lumin, Vol. 155, 2014, pp. 95-100, https://doi.org/10.1016/j.jlumin.2014.06.029.

[16] P. Dorenbos, Thermal Quenching of $\mathrm{Eu}^{2+} 5 \mathrm{~d}-4 \mathrm{f}$ Luminescence in Inorganic Compounds, J. Phys.: Condens. Matter, Vol. 17, No. 50, 2005, pp. 8103-8111, https://doi.org/10.1088/0953-8984/17/50/027.

[17] N. N. Trac, H. V. Tuyen, V. X. Quang, M. Nogami, L. V. K. Bao, N. T. Thanh, N. M. Son, N. T. T. An, L. X. Hung, T. T. Hong, Energy Level of Lanthanide Ions and Anomalous Emission of $\mathrm{Eu}^{2+}$ in $\mathrm{Sr}_{3} \mathrm{~B}_{2} \mathrm{O}_{6} \mathrm{Materials}_{\text {, Physica }}$ B: Condens. Matter, Vol. 595, 2020, pp. 412373:1-412373:7, https://doi.org/10.1016/j.physb.2020.412373.

[18] Y. Q. Li, N. Hirosaki, R. J. Xie, T. Takeda, M. Mitomo, Yellow-orange-emitting CaAlSiN $3: \mathrm{Ce}^{3+} \mathrm{Phosphor:}^{2}$ Structure, Photoluminescence, and Application in White LEDs, Chem. Mater, Vol. 20, No. 21, 2008, pp. 67046714, https://doi.org/10.1021/cm801669x. 
[19] A. H. Krumpel, E. van der Kolk, D. Zeelenberg, A. J. J. Bos, K. W. Krämer, P. Dorenbos, Lanthanide 4f-level Location in Lanthanide Doped and Cerium-lanthanide Codoped $\mathrm{NaLaF}_{4}$ by Photo- and Thermoluminescence, J. Appl. Phys, Vol. 104, No. 7, 2008, pp. 073505:1-073505:10, https://doi.org/10.1063/1.2955776.

[20] C. K. Chang, T. M. Chen, $\mathrm{Sr}_{3} \mathrm{~B}_{2} \mathrm{O}_{6}: \mathrm{Ce}^{3+}, \mathrm{Eu}^{2+}$ : A Potential Single-phased White-emitting Borate Phosphor for Ultraviolet Light-emitting Diodes, Appl. Phys. Lett, Vol. 91, No. 8, 2007, pp. 081902:1-081902:3, https://doi.org/10.1063/1.2772195.

[21] P. Dorenbos, $\mathrm{Ce}^{3+} 5 \mathrm{~d}$-centroid Shift and Vacuum Referred 4f-electron Binding Energies of all Lanthanide Impurities in 150 Different Compounds, J. Lumin, Vol. 135, 2013, pp. 93-104, https://doi.org/10.1016/j.jlumin.2012.09.034.

[22] P. Dorenbos, A Review on How Lanthanide Impurity Levels Change with Chemistry and Structure of Inorganic Compounds, ECS J. Solid State Sci. Technol, Vol. 2, No. 2, 2013, pp. R3001-R3011, https://doi.org/10.1149/2.001302jss.

[23] P. Dorenbos, Charge Transfer Bands in Optical Materials and Related Defect Level Location, Opt. Mater, Vol. 69, 2017, pp. 8-22, https://doi.org/10.1016/j.optmat.2017.03.061.

[24] P. Dorenbos, The Eu ${ }^{3+}$ Charge Transfer Energy and the Relation with the Band Gap of Compounds, J. Lumin, Vol. 111, No. 2, 2005, pp. 89-104, https://doi.org/10.1016/j.jlumin.2004.07.003.

[25] Z. J. Zhang, W. Yang, Luminescence Characteristic of RE ( RE = Pr, Sm, Eu, Tb, Dy) and Energy Levels of Lanthanide Ions in $\mathrm{Gd}_{5} \mathrm{Si}_{3} \mathrm{O}_{12} \mathrm{~N}$, Solid State Sci, Vol. 72, 2017, pp. 64-70, https://doi.org/10.1016/j.solidstatesciences.2017.08.015.

[26] Y. Q. Li, N. Hirosaki, R. J. Xie, M. Mitomo, Crystal, Electronic and Luminescence Properties of $\mathrm{Eu}^{2+}-\mathrm{doped} \mathrm{Sr}_{2} \mathrm{Al}_{2-}$ ${ }_{x} \mathrm{Si}_{1+\mathrm{x}} \mathrm{O}_{7-\mathrm{x}} \mathrm{N}_{\mathrm{x}}$, Sci. Technol. Adv. Mater, Vol. 8, No. 7, 2007, pp. 607-616, https://doi.org/10.1016/j.stam.2007.08.007. 